Jesús Villar

Jesús Blanco

José Manuel Añón

Antonio Santos-Bouza

Lluís Blanch

Alfonso Ambrós

Francisco Gandía

Demetrio Carriedo

Fernando Mosteiro

Santiago Basaldúa

Rosa Lidia Fernández

Robert M. Kacmarek

on behalf of the ALIEN Network

\title{
The ALIEN study: incidence and outcome of acute respiratory distress syndrome in the era of lung protective ventilation
}

Received: 16 May 2011

Accepted: 31 August 2011

Published online: 14 October 2011

(C) Copyright jointly held by Springer and ESICM 2011

On behalf of the ALIEN Network.

Members of the ALIEN Network are listed in the Appendix.

Electronic supplementary material

The online version of this article (doi:10.1007/s00134-011-2380-4) contains supplementary material, which is available to authorized users.

J. Villar · J. Blanco $\cdot$ L. Blanch .

S. Basaldúa $\cdot$ R. L. Fernández

CIBER de Enfermedades Respiratorias,

Instituto de Salud Carlos III, Madrid, Spain

J. Villar · R. L. Fernández

Multidisciplinary Organ Dysfunction

Evaluation Research Network, Research

Unit, Hospital Universitario Dr. Negrin, Las

Palmas de Gran Canaria, Spain

\section{J. Blanco}

Intensive Care Unit, Hospital Universitario

Río Hortega, Valladolid, Spain

\section{J. M. Añón}

Intensive Care Unit, Hospital Virgen de La Luz, Cuenca, Spain

\section{A. Santos-Bouza}

Intensive Care Unit, Complejo Hospitalario Universitario de Santiago, Santiago de

Compostela, Spain

L. Blanch

Critical Care Center, Corporació Sanitaria

Parc Taulí, Sabadell, Spain

\section{A. Ambrós}

Intensive Care Unit, Hospital General de

Ciudad Real, Ciudad Real, Spain

F. Gandía

Intensive Care Unit, Hospital Clínico

Universitario de Valladolid,

Valladolid, Spain

D. Carriedo

Intensive Care Unit, Hospital General de León, León, Spain

F. Mosteiro

Intensive Care Unit, Complejo Hospitalario Universitario de La Coruña, La Coruña, Spain

\section{S. Basaldúa}

Research Unit, Hospital Universitario NS de Candelaria, Tenerife, Spain

R. M. Kacmarek (

Department of Respiratory Care,

Massachusetts General Hospital, 55 Fruit St,

Boston, MA 01460, USA

e-mail: rkacmarek@partners.org

Tel.: +16-17-7244490

Fax: +16-17-7244495

R. M. Kacmarek

Department of Anesthesia,

Harvard University, Boston, MA, USA

J. Villar (๘)

Translational Research on Organ

Dysfunction, Research Unit, Hospital

Universitario Dr. Negrin, Barranco de la

Ballena s/n, 4th floor-South wing,

35010 Las Palmas, Spain

e-mail: jesus.villar54@gmail.com

Tel.: +34-92-8449413

Fax: +34-92-8449813
Abstract Purpose: While our understanding of the pathogenesis and management of acute respiratory distress syndrome (ARDS) has improved over the past decade, estimates of its incidence have been controversial. The goal of this study was to examine ARDS incidence and outcome under current lung protective ventilatory support practices before and after the diagnosis of ARDS. Methods: This was a 1-year prospective, multicenter, observational study in 13 geographical areas of Spain (serving a population of 3.55 million at least 18 years of age) between November 2008 and October 2009. Subjects comprised all consecutive patients meeting AmericanEuropean Consensus Criteria for ARDS. Data on ventilatory management, gas exchange, hemodynamics, and organ dysfunction were collected. Results: A total of 255 mechanically ventilated patients fulfilled the ARDS definition, representing an incidence of 7.2/100,000 population/ year. Pneumonia and sepsis were the most common causes of ARDS. At the time of meeting ARDS criteria, mean $\mathrm{PaO}_{2} / \mathrm{FiO}_{2}$ was

$114 \pm 40 \mathrm{mmHg}$, mean tidal volume was $7.2 \pm 1.1 \mathrm{ml} / \mathrm{kg}$ predicted body weight, mean plateau pressure was $26 \pm 5 \mathrm{cmH}_{2} \mathrm{O}$, and mean positive end-expiratory pressure (PEEP) was $9.3 \pm 2.4 \mathrm{cmH}_{2} \mathrm{O}$. Overall ARDS intensive care unit (ICU) and hospital 
mortality was $42.7 \%$ (95\% CI

$37.7-47.8)$ and $47.8 \%$ (95\%CI

42.8-53.0), respectively. Conclu-

sions: This is the first study to prospectively estimate the ARDS incidence during the routine application of lung protective ventilation.
Our findings support previous estimates in Europe and are an order of magnitude lower than those reported in the USA and Australia. Despite use of lung protective ventilation, overall ICU and hospital mortality of ARDS patients is still higher than $40 \%$.
Keywords Incidence.

Acute respiratory distress syndrome . Lung protective mechanical ventilation · Prognosis

\section{Introduction}

Acute respiratory distress syndrome (ARDS) is a complication of a variety of diseases [1]. Currently, the diagnosis of ARDS is made by a history of a predisposing illness, acute onset, bilateral pulmonary infiltrates on chest X-ray, and severe hypoxemia [2]. While our understanding of the pathogenesis, risk factors, complications, and management has improved over the past two decades [3], estimates of the incidence of ARDS have been controversial. The main reasons for the fluctuation of incidence data may be the various definitions of ARDS used and difficulties in identifying all cases in a given geographical area [4-10]. Reported data for the incidence of ARDS in the USA would suggest a figure that is greatly in excess of that expected by current clinical experience in Europe. The first estimate of the incidence of ARDS was based on a National Heart and Lung Institute (NHLI) task force report in 1972 [11], citing a figure of 150,000 cases per year in the USA. Assuming a population of 200 million for the USA during the early 1970 s, this represents an incidence of 75/100,000 population/year. That report defined ARDS as acute respiratory failure associated with a number of clinical conditions including infantile respiratory distress syndrome, disseminated intravascular coagulation, viral pneumonia, acute renal failure, drug overdose, burns, and fluid overload. This definition is very different from the current definition of ARDS [2]. Using the current definition, Rubenfeld et al. [10] reported a 58.7/100,000/year ARDS incidence in a cohort of patients undergoing mechanical ventilation (MV) admitted to 21 US hospitals from April 1999 to July 2000. The first prospective European study was performed by Villar and Slutsky [5] in the Canary Islands, Spain, from 1983 to 1985 . They reported an ARDS incidence of 3.5/100,000/year, a figure that was validated by other epidemiological studies in England [4], Germany [6], and Finland [8].

There is now unequivocal evidence that MV can cause or aggravate acute lung injury [12]. This condition resembles ARDS and it has prompted a number of investigators to suggest that ARDS may in part be a product of our efforts to ventilate patients rather than the progression of the underlying disease [13]. The ARDS Network study in 2000 provided convincing evidence that MV affects outcome [14]. Within the context of extreme variability among the few published epidemiological studies on ARDS and in light of the use of lung protective ventilation, we performed a 1-year study to determine the incidence, etiology, and outcome of ARDS in adults in Spain under the current ARDS definition and using protective MV practices before and after the diagnosis of ARDS.

\section{Methods}

Study design and patients

This observational study was approved by the institutional ethics committees of participating centers. This study was considered an audit and informed consent was waived because data were analyzed anonymously. All consecutive patients meeting the American-European consensus conference (AECC) definition for ARDS [2] who were admitted during the period November 2008 to October 2009 to 13 geographical catchment areas in Spain covered by a network of 17 hospitals ( 354 critical care beds) under the acronym ALIEN (Acute Lung Injury: Epidemiology and Natural history) were included. The 13 geographical catchment areas included two provinces of Galicia, seven provinces of Castilla-León, three provinces of Castilla-La Mancha, and the city of Sabadell in the region of Cataluña (see Appendix). Each hospital provided medical care for a specific geographical health-care area defined by the Spanish Health Care System. These 17 hospitals were the only providers of critical care for the 13 geographical areas. The total number of residents at least 18 years of age in these health-care areas was obtained from the Spanish census data for 2008 published by the Spanish National Statistics Institute (http://www.ine.es; accessed 2 June 2010) [see Electronic Supplementary Material (ESM) for more details].

Data collection and quality control

All intensive care unit (ICU) admissions were screened daily for ARDS (see ESM for details). Physicians only considered blood gas values while patients were clinically stable and did not consider a transient fall in $\mathrm{PaO}_{2} / \mathrm{FiO}_{2}$ 
resulting from an acute event unrelated to the disease process (such as patient-ventilator asynchrony, obstruction of the endotracheal tube by secretions, suctioning, sudden pneumothorax, and hemodynamic instability). Onset of ARDS was defined as the day on which the patient first met all AECC criteria. MV and hemodynamics data were collected on days $0,1,3,7$, and the last day of MV. The end-inspiratory plateau pressure was determined by application of an end-inspiratory pause of sufficient time, as determined by the investigator, to ensure airway pressure equilibrium (more than $1.0 \mathrm{~s}$ ). Acute physiology and chronic health evaluation (APACHE) II [15] score and lung injury score (LIS) [16] were recorded. Clinical and laboratory data for the APACHE II score were collected within the first $24 \mathrm{~h}$ after ICU admission. Standard definitions for sepsis and organ failure were used [17-19]. Extrapulmonary organ failure included in the sequential organ failure assessment (SOFA) scale was documented daily [17]. Any organ failure occurring during the 6-h period before death was considered part of the terminal event and not counted.

Physiological and biological data were checked against standardized ranges by a trained data manager at the coordinating center (see ESM for details). Age, gender, predicted body weight (PBW), risk factors for ARDS, $\mathrm{PaO}_{2} / \mathrm{FiO}_{2}$ ratio at the time of ARDS identification, and severity scores were checked and reassessed at the coordinating center. If inconsistencies were found, the site principal investigator was contacted to clarify and make the corrections accordingly.

\section{General management}

Although patient care was not strictly protocolized, physicians were asked to follow the current standards for the general management of critically ill patients (see ESM for details). None of the patients in this cohort received activated protein $\mathrm{C}$, low doses of corticosteroids, or nitric oxide as an adjunctive treatment. For ventilatory management, it was recommended that all patients with acute respiratory failure or acute lung injury be ventilated with a tidal volume $\left(V_{\mathrm{T}}\right)$ of $4-8 \mathrm{ml} / \mathrm{kg}$ PBW [20] at a ventilatory rate to maintain $\mathrm{PaCO}_{2}$ at $35-50 \mathrm{mmHg}$, a plateau pressure less than $30 \mathrm{cmH}_{2} \mathrm{O}$, and with positive endexpiratory pressure (PEEP) and $\mathrm{FiO}_{2}$ combinations to maintain $\mathrm{PaO}_{2}$ above $60 \mathrm{mmHg}$ or $\mathrm{SpO}_{2}$ above $90 \%$. None of the participating centers used extracorporeal membrane oxygenation or high-frequency ventilation.

Outcome measures and statistical analysis

The primary goal of this study was to determine the incidence of adult ARDS requiring MV in Spain, expressed as cases per 100,000 inhabitants per year in the population at least 18 years old. Data are expressed as percentages, means \pm standard deviation (SD), or medians and interquartile ranges (IQR). Differences between distributions of categorical variables were analyzed by Pearson's $\chi^{2}$ or Fisher's exact tests. For continuous variables, the data were analyzed using Student's $t$ and Mann-Whitney $U$ tests, depending on their distribution. Secondary outcomes were ICU and hospital mortality rates. The $95 \%$ confidence intervals (CI) for mortality rate were computed using Jeffrey's interval for a binomial proportion. A two-sided $p$ value no greater than 0.05 was considered significant. Data analyses were performed using SPSS (IBM SPSS Statistics 19, Chicago, IL, US).

\section{Results}

From November 2008 to October 2009, there were a total of 11,363 ICU admissions and 3,462 patients requiring MV for at least $24 \mathrm{~h}$ in all catchment areas. The total number of mechanically ventilated patients meeting the AECC definition for ARDS was 255 (2.2\% of ICU admissions and $7.4 \%$ of those who received MV for at least $24 \mathrm{~h}$ ) representing a crude incidence of 5.9/100,000/ year and an incidence of 7.2/100,000/year when considering the population at least 18 years of age. Median age was 58 years (IQR 41-73) and 70.6\% were males.

Mean baseline $\mathrm{PaO}_{2} / \mathrm{FiO}_{2}$ ratio was $114 \pm 40 \mathrm{mmHg}$ and mean APACHE II score was $21.6 \pm 5.9$. Pneumonia and sepsis were the primary cause of ARDS in 42.3 and $31.4 \%$ of patients, respectively (Table 1). All centers verified that they screened every patient for ARDS that entered their ICU during the study period. At the time of meeting ARDS criteria, mean $V_{\mathrm{T}}$ was $7.2 \pm 1.1 \mathrm{ml} / \mathrm{kg}$ PBW (range $4.0-8.4 \mathrm{ml} / \mathrm{kg}$ PBW), mean plateau pressure was $26 \pm 5 \mathrm{cmH}_{2} \mathrm{O}$, and mean PEEP was $9.3 \pm 2.4$ $\mathrm{cmH}_{2} \mathrm{O}$ (Table 1). At baseline, applied PEEP ranged from 4 to $15 \mathrm{cmH}_{2} \mathrm{O}$. However, after making the diagnosis of ARDS, most patients $(87 \%)$ were treated with PEEP at least $10 \mathrm{cmH}_{2} \mathrm{O}$ and $14 \%$ received 15 to $24 \mathrm{cmH}_{2} \mathrm{O}$ of PEEP (Fig. E1, ESM). Pneumothorax developed in $8.1 \%$ of patients. $\mathrm{PaO}_{2} / \mathrm{FiO}_{2}$ ratio at the time of ARDS identification had an inverse relationship to mortality $(p=0.005)$ (Fig. 1). For ventilatory, gas exchange, and hemodynamic data during ICU stay, see Table E1 (ESM). Prone positioning was used in $17.2 \%$ of patients $(44 / 255)$. Twenty of them died (mortality 45.4\%).

Overall ARDS ICU mortality was $42.7 \%$ (95\%CI $37.7-47.8)$ and hospital mortality was $47.8 \%$ (95\% CI 42.8-53.0) (Table 1). ICU mortality rates ranged between 33 and 55\% among participating centers. When evaluating this range in relation to the number of ICU admissions, ICU beds in each center, type of patients, ARDS cases enrolled during the 12-month period in each 
Table 1 Demographics and general clinical data from 255 patients with ARDS

\begin{tabular}{|c|c|}
\hline Variable & Values \\
\hline Age, median $\left(\mathrm{P}_{25}-\mathrm{P}_{75}\right)$, years & $58(41-73)$ \\
\hline Males/females \% & $70.6 / 29.4$ \\
\hline APACHE II score & $21.6 \pm 5.9$ \\
\hline LIS at ARDS onset & $2.9 \pm 0.6$ \\
\hline Days in the hospital, median $\left(\mathrm{P}_{25}-\mathrm{P}_{75}\right)$ & $35(19-64)$ \\
\hline Days in the ICU, median $\left(\mathrm{P}_{25}-\mathrm{P}_{75}\right)$ & $22(13-36)$ \\
\hline Days on $\mathrm{MV}$, median $\left(\mathrm{P}_{25}-\mathrm{P}_{75}\right)$ & $17(10-29)$ \\
\hline $\mathrm{PaO}_{2} / \mathrm{FiO}_{2}$ at $\mathrm{ARDS}$ onset $\mathrm{mmHg}$ & $114 \pm 40$ \\
\hline$V_{\mathrm{T}}, \mathrm{ml} / \mathrm{kg}$ PBW (at ARDS onset) & $7.2 \pm 1.1$ \\
\hline PEEP, $\mathrm{cmH}_{2} \mathrm{O}$ (at ARDS onset) & $9.3 \pm 2.4$ \\
\hline Plateau pressure, $\mathrm{cmH}_{2} \mathrm{O}$ (at ARDS onset) & $26 \pm 4$ \\
\hline Number of failing organs at ARDS onset & $1.5 \pm 1.1$ \\
\hline Pneumothorax after initiation of MV, $n(\%)$ & $24(8.1)$ \\
\hline ICU mortality, $n(\%)$ & $109(42.7)$ \\
\hline Hospital mortality, $n(\%)$ & $122(47.8)$ \\
\hline \multicolumn{2}{|l|}{ Causes of ARDS, $n(\%)$} \\
\hline Pneumonia & $108(42.3)$ \\
\hline Sepsis & $80(31.4)$ \\
\hline Trauma & $24(9.4)$ \\
\hline Aspiration & $21(8.2)$ \\
\hline Pancreatitis & $12(4.7)$ \\
\hline Overdose/poisoning & $4(1.6)$ \\
\hline Others & $6(2.3)$ \\
\hline
\end{tabular}

Values are expressed as mean $\pm \mathrm{SD}$, unless indicated otherwise $P_{25}-P_{75} 25$ th and 75 th IQR

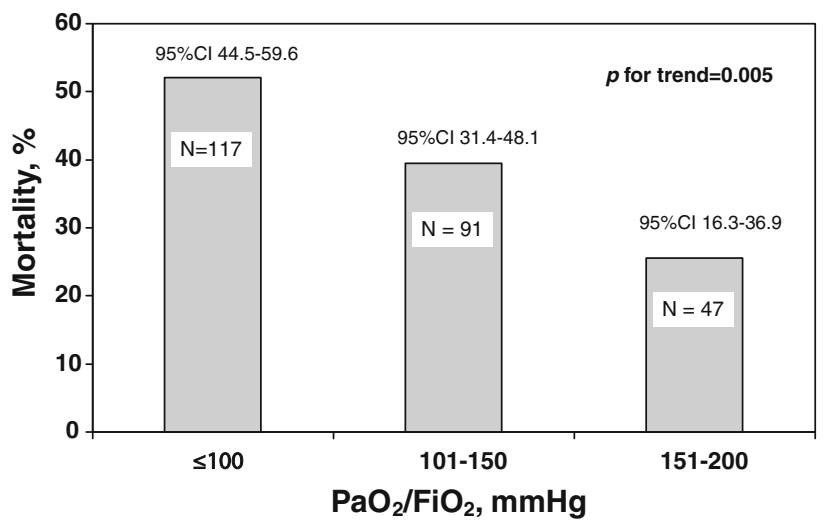

Fig. 1 Number of ARDS patients and mortality by the degree of hypoxemia (measured as $\mathrm{PaO}_{2} / \mathrm{FiO}_{2}$ ratio) at ARDS onset. Fortysix percent of patients $(N=117)$ had a $\mathrm{PaO}_{2} / \mathrm{FiO}_{2}$ no greater than $100 \mathrm{mmHg}$. $N$ total number of patients in each category, $95 \% \mathrm{CI}$ 95\% confidence intervals for mortality rate in each subgroup

ICU, and ARDS etiologies, we did not find any significant correlation with mortality. However, larger hospitals had larger ICUs and higher numbers of enrolled ARDS cases. One hundred and forty-six out of 255 patients (57\%) met ARDS criteria at the day of ICU admission (71 deaths, mortality $48.6 \%$ ). One of those patients died within the first $24 \mathrm{~h}$ of ICU admission. Less than half of patients $(109 / 255,43 \%)$ developed ARDS after ICU admission (38 deaths, mortality $34.9 \%$ ). When comparing mortality of ARDS on admission vs. ARDS during ICU stay, the $13.7 \%$ absolute mortality difference was statistically significant $(p=0.028)$. Of the ICU deaths, $21.1 \%$ occurred during the first week and $39.4 \%$ within the first 14 days after the onset of ARDS. Two patients died $24 \mathrm{~h}$ after meeting ARDS criteria. We did not find any statistically significantly differences between survivors and nonsurvivors when analyzing demographic data, disease severity scores, and physiologic and respiratory variables recorded during the first $24 \mathrm{~h}$ of ARDS (Table E2, ESM).

Multiple system organ failure was the most frequent cause of death (45.8\%) and the greater the number of failing organs, the greater was the mortality $(p<0.00001)$ (Fig. E2, ESM). The presence of shock had no impact in the overall ARDS outcome (Table E2). Refractory hypoxemia was the cause of death in 21 patients $(19.3 \%)$.

\section{Discussion}

Our study shows that the current incidence of ARDS in Spain in the era of protective MV is in the range of estimates provided by previous European epidemiological studies $[4-9,21]$. This figure is dramatically lower than the $75 / 100,000$ usually quoted in the literature [11] and the $58.7 / 100,000$ [10] and 33.8/100,000 [22] recently reported in the USA. There are a number of possible explanations for this large discrepancy. Some reports have used different definitions for ARDS, others have analyzed the data retrospectively, and others only evaluated the incidence during a short period (less than 10 weeks) and then extrapolated their findings. Among the six main published reports on ARDS incidence using the AECC definition [8-10, 21-23] (Table 2), the study by Rubenfeld et al. [10] in the USA and the present study in Spain are the only ones that used the AECC definition and collected data for a 1-year period. Rubenfeld et al. estimated the incidence of ARDS in 21 hospitals from a US county with a population of 1.74 million for 12 consecutive months from April 1999 to July 2000. All patients who underwent MV for at least $24 \mathrm{~h}$ were screened and the arterial blood gas values with the worst $\mathrm{PaO}_{2} / \mathrm{FiO}_{2}$ ratio were used to classify patients as ARDS. They identified 828 patients meeting ARDS criteria. Li et al. [22] performed a retrospective analysis of patients admitted over an 8-year period from 2001 to 2008 in two hospitals serving a US county with a population of 124,277 . Using what they called "an electronic ARDS screening tool", they reviewed charts focusing on recorded information for qualifying chest $\mathrm{X}$-rays and $\mathrm{PaO}_{2} / \mathrm{FiO}_{2}$ ratio. They identified 514 ARDS cases over the 8 years (42 in 2008), representing an incidence in 2008 of 33.8/100,000. Current clinical practice in Europe does not support such a high prevalence of ARDS patients [6, 21, 24, 25]. 


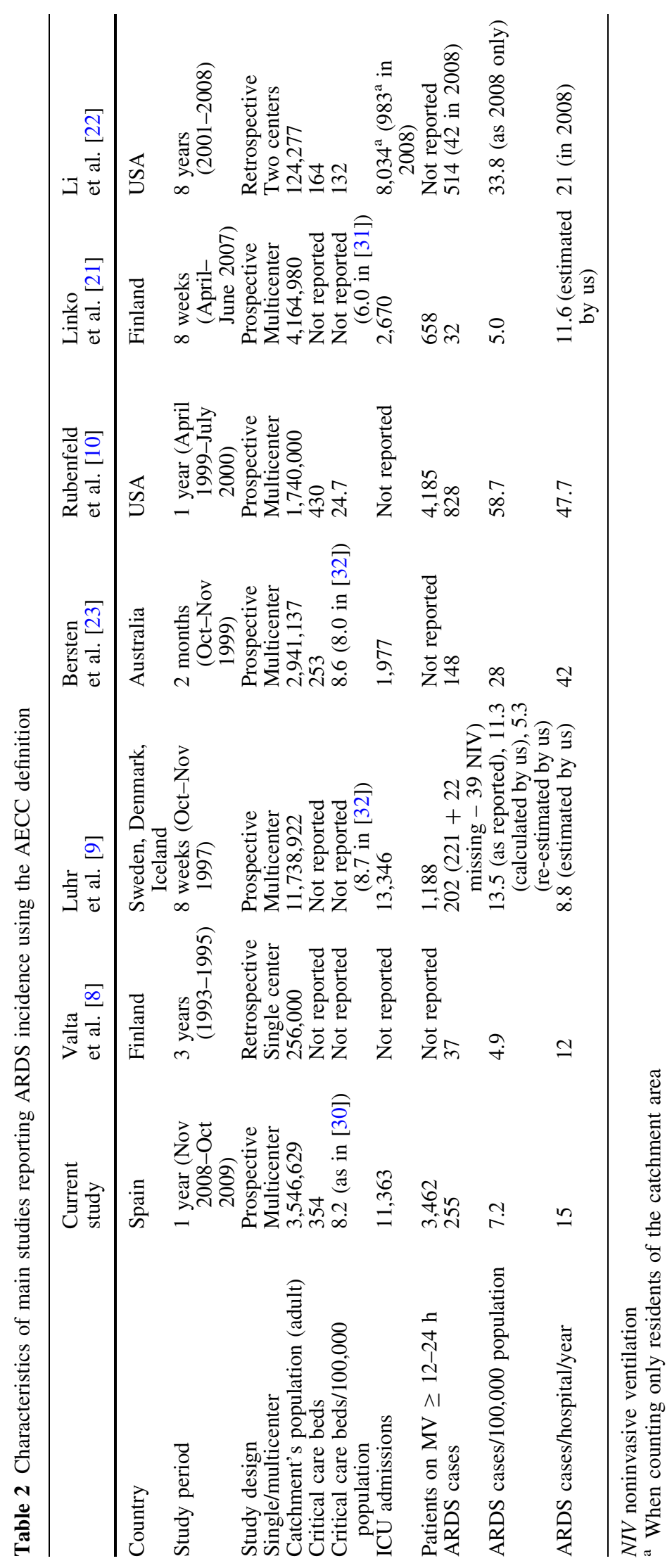


Prior to the AECC definition, Fowler et al. [26] identified in a 1-year prospective study in Denver, Colorado, 88 patients with ARDS using a $\mathrm{PaO}_{2} / \mathrm{P}_{\mathrm{A}} \mathrm{O}_{2}$ ratio no greater than 0.2. On the basis of this figure, we estimated the incidence of ARDS to be 5.2/100,000/year. Webster et al. [4] performed a retrospective survey without standard criteria for the diagnosis of ARDS and reported a 1-year ARDS incidence of 4.5/100,000 in a British health district with a population of 3.5 million. In 1989, Villar and Slutsky [5] reported the results of a 3-year (1983-1985) prospective study on the incidence of ARDS in a closed island population, performed a decade before the publication of the AECC definition for ARDS and almost two decades before the publication of the ARDSNet trial. There are several important differences between the first Spanish incidence study and the current one. The 74 ARDS patients reported in the former study (representing an incidence of 3.5 cases/100,000 population/year) had the following distinct features: (i) patients were admitted into a single-center ICU; (ii) arterial hypoxemia for ARDS was defined as a $\mathrm{PaO}_{2} / \mathrm{FiO}_{2}$ no greater than $150 \mathrm{mmHg}$ on $\mathrm{FiO}_{2}$ at least 0.5 with PEEP at least $5 \mathrm{cmH}_{2} \mathrm{O}$, very different from the current AECC definition in which the limit for $\mathrm{PaO}_{2} / \mathrm{FiO}_{2}$ is $200 \mathrm{mmHg}$ regardless of PEEP level; (iii) $V_{\mathrm{T}}$ ranged between 8 and $15 \mathrm{ml} / \mathrm{kg}$ actual body weight at a respiratory rate necessary to maintain a $\mathrm{PaCO}_{2}$ of $35-45 \mathrm{mmHg}$; (iv) the therapeutic goal for blood transfusion was to maintain a hemoglobin concentration of $10-15 \mathrm{~g} / \mathrm{dl}$ (well above current recommendations); (v) peak inspiratory pressures were allowed to surpass $40 \mathrm{cmH}_{2} \mathrm{O}$; (vi) overall ICU mortality rate was 50\%. In 1991, Lewandowski et al. [6] performed a 2-month prospective study in 72 ICUs from Berlin, Germany (total population 3.44 million) and identified 17 patients with ARDS (as defined by LIS greater than 2.5), representing an incidence of 3/100,000/ year, although this figure was not adjusted for the adult population. In 1992, Thomsen et al. [7] performed a 1-year survey of ARDS incidence in the State of Utah using a $\mathrm{PaO}_{2} / \mathrm{P}_{\mathrm{A}} \mathrm{O}_{2}$ no greater than 0.2 and estimated an ARDS incidence of 4.8-8.3/100,000/year.

Using the AECC definition, Valta et al. [8] in a 3-year (1993-1995) retrospective analysis on a Finish reference population of 256,000 inhabitants, and Linko et al. [21] in an 8 -week prospective study 12 years later in the entire country of Finland, found an incidence of 4.9/100,000 and 5.0/100,000, respectively. Luhr et al. [9] also performed an 8-week survey in all ICUs from Sweden, Denmark, and Iceland, with a combined population of 11.7 million. They identified 221 patients with ARDS and calculated an extra 22 patients for those patients in the few nonparticipating ICUs, estimating an incidence of 13.5/100,000/ year. However, a critical appraisal of that study suggests a misclassification bias. First, 39 of those 221 patients were nonintubated and treated with an oxygen face mask or NIV. Second, $78 \%$ of the identified ARDS cases had a pulmonary origin but in $48 \%$ of them $(n=106)$ the specific cause for the development of ARDS included very different entities that do not qualify as risk factors for ARDS, such as chronic obstructive pulmonary disease, atelectasis, cardiogenic pulmonary edema, pneumothorax, and pleural effusion. Third, although a LIS greater than 2.5 is not specific for ARDS because it is not clear whether patients with identical scores have similar degrees of lung injury [27], it is worthy to remark that only 119 patients had a LIS greater than 2.5 , representing an incidence of 7.6/100,000. Fourth, as reported in Luhr et al.'s article, there was a lack of differences in the mortality rate between ARDS and acute lung injury (ALI) and acute respiratory failure (about $41-42 \%$ in each of them), a finding that has not been validated by others $[6$, $24,28]$. Therefore, taking into consideration all the above, we have estimated the "true" ARDS incidence in those three countries as 5.3/100,000 population, a similar figure to the one reported for Finland, another Scandinavian country $[8,21]$.

The 28/100,000 figure for ARDS incidence in Australia reported by Bersten et al. [23] could represent another example of misclassification bias. They screened patients for the development of ALI and ARDS admitted into 21 ICUs during a 2-month period in 1999. They identified 148 patients as having ARDS but only 20 patients as having ALI. Although the AECC physiological thresholds for separating ALI from ARDS do not require standardized ventilatory support, it is well accepted that a small increase of $\mathrm{FiO}_{2}$ and a moderate level of PEEP can improve oxygenation sufficiently to convert patients meeting the definition of ARDS on PEEP less than $5 \mathrm{cmH}_{2} \mathrm{O}$ and $\mathrm{FiO}_{2}$ less than 0.40 to have ALI, and can change lung physiology in these patients to an extent that they do not meet the criteria for ALI or ARDS [28]. Looking at their initial ventilatory parameters, it seems that as many as half of the ALI/ARDS patients were treated with PEEP no greater then $3 \mathrm{cmH}_{2} \mathrm{O}$ and/or $\mathrm{FiO}_{2}$ less than 0.40. In addition, the mean $V_{\mathrm{T}}$ was close to $12 \mathrm{ml} / \mathrm{kg}$ PBW. Since this short-term observational study was performed before the publication of the ARDSNet trial, the values of the initial ventilatory settings and the reported overall low ICU mortality rate for ARDS (30\%) may substantially affect the validity of the estimated high ARDS incidence in Australia.

Demographic, cultural, economical, and health-care system differences between the USA and Europe [29] may also account for the order of magnitude difference between our study (as well other European studies) and Rubenfeld's. It is plausible that variations in the number of ICU beds, hospital policy on ICU bed utilization, ICU staffing, and burden of disease requiring ICU admission influenced the number of patients admitted into the ICU and diagnosed as having ARDS [30-32]. The number of ICU beds in Europe varied from 3.5 (UK) to 24.6 per 100,000 population (Germany). In our study, the 


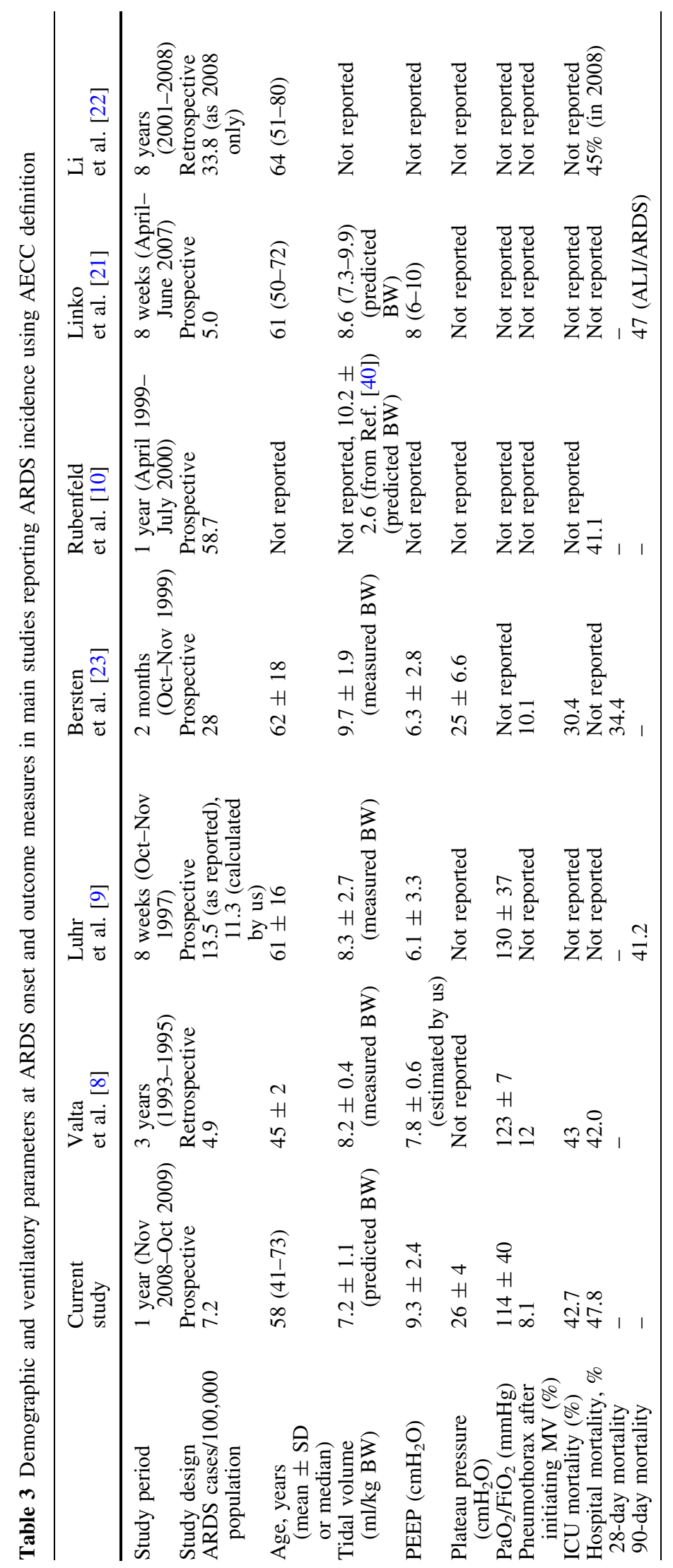


catchment area had 8.2 adult ICU beds per 100,000 population, the same value that was previously estimated for the whole of Spain [30-32]. When compared to countries with similar ICU-bed availability, our ARDS incidence is very similar to that recently estimated or recalculated by us in the studies from Finland (with 6 ICU beds/100,000 population) [31], Australia (8.0 ICU beds/ 100,000 population [32], and Sweden (8.7 ICU beds/ 100,000 population) [32] (Table 2). In a recent retrospective analysis, Charron et al. [25] from France reported their experience with 218 ARDS patients admitted during a 13-year period (1997-2009) in a single ICU. With an average of 8.4 beds $/ 100,000$ population in their ICU during the study period [30-32], the number of ARDS patients admitted per year was 16.7 , very similar to the 15 ARDS patients/hospital/year in our study. ICUs in the USA admit many more patients than European and Canadian ICUs [33]. Our incidence of ICU admissions was $264.3 / 100,000 /$ year, remarkably similar to the $263.7 /$ $100,000 /$ year reported by Laupland in Canada [34]. In a retrospective analysis from nonfederal hospitals in six US states in 1999, Angus et al. [35] found that almost 1 in 5 (22.4\%) US citizens died using ICU services, a figure that is greatly in excess of that in Europe. As stated in the reports by Rubenfeld et al. [10] and $\mathrm{Li}$ et al. [22], the demographic features of their catchment area are not identical to those of the USA as a whole. Also, our catchment area represents $9.4 \%$ of the population of Spain whereas the catchment area in the Rubenfeld et al. report represented $0.6 \%$ of the population of the USA.

Our study is the first to prospectively estimate the incidence of ARDS during the application of a lung protective MV strategy [14]. In most epidemiological studies of ARDS, including those using the AECC definition, patients were treated with a $V_{\mathrm{T}}$ above current recommendations (4-8 ml/kg PBW) (Table 3). The $V_{\mathrm{T}}$ and PEEP levels used at baseline and within the first $24 \mathrm{~h}$ of ARDS onset in our study were in the same range as those used in recent clinical trials evaluating the effects of ventilatory support on ARDS outcome [36-39]. Although not reported in the original paper, patients in the Rubenfeld et al. study [10] were treated with an average $V_{\mathrm{T}}$ greater than $10 \mathrm{ml} / \mathrm{kg}$ [40]. It has been postulated that the incidence of ARDS should have decreased over the past 10 years because of advances in supportive care, particularly the application of low- $V_{\mathrm{T}}$ MV $[13,22,41]$. Our study design makes it impossible to investigate or demonstrate the role of lung protective MV in changes in the incidence or outcome of patients with ARDS, although it can be argued that the incidence of ARDS in Europe has not changed over the last 20 years. However, when comparing the Rubenfeld et al. [10] data with the Li et al. [22] data, it is plausible to speculate that changes in hospital practice from 1999 to 2009 could explain the decreasing incidence of hospital-acquired ARDS, as reported by $\mathrm{Li}$ et al.
Finally, the overall ICU and hospital mortality rates (42.7 and $47.8 \%$, respectively) of our cohort validate the estimates of a recent systematic review of 53 observational studies by Phua et al. [42] in which they found that the pooled mortality for ARDS from 1994 to 2006 was $44 \%$. They also found that the definition of ARDS was not an independent predictor of mortality and that this mortality rate is consistently higher than that reported in randomized control trials [35]. Our findings raise the question of why mortality for patients with ARDS has not improved in the context of protective MV. However, Phua et al. also found that although the pooled ARDS mortality was lower in randomized controlled trials $(36.2 \%)$, the extent to which protective MV affects mortality in all ARDS patients is currently unclear.

In summary, our study is the first to prospectively estimate the incidence of ARDS during the application of lung protective MV. Our results are consistent with other European ARDS incidence studies but are of a magnitude about 5-10 times less than the incidence of ARDS in the USA. Most concerning is the fact that it seems that the incidence and mortality of ARDS have not changed in Europe 10 years after the original ARDSnet study.

Acknowledgments Supported in part by grants from the Instituto de Salud Carlos III, Spain (PI 07/0113, CB06/06/1088).

Conflict of interest All authors declared that they have no conflict of interest in relation to the content of this study and manuscript.

\section{Appendix}

Academic center staff: investigators of the ALIEN

Network

- Hospital Universitario Dr. Negrín, Las Palmas de Gran Canaria: Jesús Villar, MD, PhD (principal investigator) and Rosa Lídia Fernández, MBA (study coordinator).

- Hospital Universitario Río Hortega, Valladolid: Jesús Blanco, MD, PhD (study coordinator) and Arturo Muriel, MD (study physician).

- Hospital Clínico Universitario de Valladolid, Valladolid: Francisco Gandía, MD (study coordinator), and David Andaluz, MD, Laura Parra, MD (study physicians).

- Hospital Río Carrión, Palencia: Javier Collado, MD, José Ignacio Alonso, MD (study physicians).

- Hospital Virgen de la Concha, Zamora: Antonio Álvarez, MD, Concepción Tarancón, MD (study physicians)

- Complejo Hospitalario de León, León: Demetrio Carriedo, MD (study coordinator), and Ana María Dominguez, MD, Javier Díaz-Domínguez, MD (study physicians). 
- Hospital Clínico de Salamanca, Salamanca: Noelia Albalá, MD, Ángel Rodríguez-Encinas, MD (study physicians).

- Hospital General de Soria, Soria: Raúl Sánchez, MD, Fabiola Tena, MD (study physicians).

- Hospital General de Segovia, Segovia: Santiago Macías, MD, Noelia Lázaro, MD (study physicians).

- Hospital General Yagüe, Burgos: Alberto Indarte, MD, María Eugenia Perea, MD (study physicians).

- Complejo Hospitalario Universitario de Santiago, Santiago de Compostela, La Coruña: Antonio SantosBouza, MD, PhD (study coordinator).

- Complejo Hospitalario Universitario de La Coruña, La Coruña: Fernando Mosteiro, MD (study coordinator).

- Complejo Hospitalario de Orense, Orense: Eleuterio Merayo, MD (study physician).

- Hospital Virgen de la Luz, Cuenca: José Manuel Añón, MD, PhD (study coordinator), and María Jesús Bruscas, MD (study physician).

- Hospital General de Ciudad Real, Ciudad Real: Alfonso Ambrós, MD (study coordinator), and Rafael del Campo, MD (study physician).
- Hospital Santa Bárbara, Puertollano, Ciudad Real: Francisca Prieto, MD (study physician).

- Complejo Hospitalario Universitario de Albacete, Albacete: José Manuel Gutiérrez, MD, and Virgilio Córcoles, MD (study physicians).

- Hospital de Hellín, Albacete: Ricardo Fernández, MD, and José Ignacio Lozano, MD (study physicians).

- Hospital La Mancha Centro, Alcázar de San Juan, Ciudad Real: Antonio García, MD, and Carmen Martín, MD (study physicians).

- Corporació Sanitaria Parc Taulí, Sabadell, Barcelona: Lluís Blanch, $\mathrm{MD}, \mathrm{PhD}$ (study coordinator), and Gemma Gomá, RN, and Gisela Gili, RN (research nurses).

- Hospital Universitario NS de Candelaria, Santa Cruz de Tenerife: Santiago Basaldúa, MSc (data manager and statistician).

- Massachussets General Hospital, Boston, Massachussets: Robert M. Kacmarek, PhD, RRT (principal coinvestigator).

\section{References}

1. Ashbaugh DG, Bigelow DB, Petty TL, Levine BE (1967) Acute respiratory distress in adults. Lancet 2:319-323

2. Bernard GR, Artigas A, Brigham KL, Carlet J, Falke K, Hudson L, Lamy M, Legall JR, Morris A, Spragg R (1994) The American-European consensus conference on ARDS: definitions, mechanisms, relevant outcomes and clinical trials coordination. Am J Respir Crit Care Med 149:818-824

3. Ware LB, Matthay MA (2000) The acute respiratory distress syndrome. N Engl J Med 342:1334-1349

4. Webster NR, Cohen AT, Nunn JF (1988) Adult respiratory distress syndrome: how many cases in the UK? Anaesthesia 43:923-926

5. Villar J, Slutsky AS (1989) The incidence of the adult respiratory distress syndrome. Am Rev Respir Dis 140:814-816

6. Lewandowski K, Metz J, Deutschmann C, Preiss H, Kuhlen R, Artigas A, Falke KJ (1995) Incidence, severity, and mortality of acute respiratory failure in Berlin, Germany. Am J Respir Crit Care Med 151:1121-1125

7. Thomsen GE, Morris AH (1995) Incidence of the adult respiratory distress syndrome in the state of Utah. Am J Respir Crit Care Med 152:965-971
8. Valta P, Uusaro A, Nunes S, Ruokonen E, Takala J (1999) Acute respiratory distress syndrome: frequency, clinical course, and costs of care. Crit Care Med 27:2367-2374

9. Luhr OR, Antonsen K, Karlsson M, Aardal S, Thorsteinsson A, Frostell CG, Bonde J, The ARF Study Group (1999) Incidence and mortality after acute respiratory failure and acute respiratory distress syndrome in Sweden, Denmark and Iceland. Am J Respir Crit Care Med 159:1849-1861

10. Rubenfeld GD, Caldwell E, Peabody E, Weaver J, Martin DP, Neff M, Stern EJ, Hudson LD (2005) Incidence and outcomes of acute lung injury. N Engl J Med 353:1685-1693

11. National Heart and Lung Institutes (1972) Respiratory diseases: task force on problems, research approaches, needs. Washington, DC, US Government Printing Office; DHEW publication NIH 74-432:167-180

12. Pinhu L, Whitehead T, Evans T, Griffiths M (2003) Ventilatorassociated lung injury. Lancet 361:332-340

13. Villar J, Kacmarek RM, Hedenstierna G (2004) From ventilator-induced lung injury to physician-induced lung injury: why the reluctance to use small tidal volumes? Acta Anaesthesiol Scand 48:267-271
14. The Acute Respiratory Distress Syndrome Network (2000) Ventilation with lower tidal volumes as compared with traditional tidal volumes for acute lung injury and the acute respiratory distress syndrome. N Engl J Med 342:1301-1308

15. Knaus WA, Draper EA, Wagner DP, Zimmerman JE (1985) APACHE II: a severity of disease classification system. Crit Care Med 13:818-829

16. Murray JF, Matthay MA, Luce JM, Flick MR (1988) An expanded definition of the adult respiratory distress syndrome. Am Rev Respir Dis 138:720-723

17. Vincent JL, de Mendonca A, Cantraine F, Moreno R, Takala J, Suter PM, Sprung CL, Colardyn F, Blecher S (1998) Use of the SOFA score to assess the incidence of organ dysfunction/ failure in intensive care units: results of a multicenter, prospective study. Working group on "sepsis-related problems" of the European Society of Intensive Care Medicine. Crit Care Med 26:1793-1800

18. Villar J, Manzano JJ, Blázquez MA, Lubillo S, Villalobos J, Quintana J (1991) Multiple system organ failure in acute respiratory failure. J Crit Care $6: 75-80$ 
19. Levy MM, Fink MP, Marshall JC, Abraham E, Angus D, Cook D, Cohen J, Opal SM, Vincent JL, Ramsay G, SCCM/ESICM/ACCP/ATS/SIS (2003) 2001 SCCM/ESICM/ACCP/ATS/SIS: international sepsis definitions conference. Crit Care Med 31:1250-1256

20. Devine BJ (1974) Gentamicin therapy. Drug Intell Clin Pharm 8:650-655

21. Linko R, Okkonen M, Pettilä V, Parviainen I, Ruokonen E, Tenhunen J, Ala-Kokko T, Varpula T, The FINNALI-study group (2009) Acute respiratory failure in intensive care units. FINNALI: a prospective cohort study. Intensive Care Med 35:1352-1361

22. Li G, Malinchoc M, Cartin-Ceba R, Venkata CV, Kor DJ, Peters SG, Hubmayr RD, Gajic O (2011) Eightyear trend of acute respiratory distress syndrome. Am J Respir Crit Care Med 183:59-66

23. Bersten AD, Edibam C, Hunt T, Moran J, The Australian, New Zeland Intensive Care Society Clinical Trials Group (2002) Incidence and mortality of acute lung injury and the acute respiratory distress syndrome in three Australian states. Am J Respir Crit Care Med 165:443-448

24. Brun-Buisson C, Minelli C, Bertolini G, Brazzi L, Pimentel J, Lewandowski K, Bion J, Romand JA, Villar J, Thorsteinsson A, Damas P, Armaganidis A, Lemaire F, ALIVE Study Group (2004) Epidemiology and outcome of acute lung injury in European intensive care units. Results from the ALIVE study. Intensive Care Med 30:51-61

25. Charron C, Bouferrache K, Caille V, Castro S, Aegerter P, Page B, Jardin F, Vieillard-Baron A (2011) Routine prone positioning in patients with severe ARDS: feasibility and impact on prognosis. Intensive Care Med 37:785-790

26. Fowler AA, Hamman RF, Good JT, Benson KN, Baird M, Eberle DJ, Petty TL, Hyers TM (1983) Adult respiratory distress syndrome: risk with common predispositions. Ann Intern Med 98:593-597

27. Meade MO, Guyatt GH, Cook RJ, Groll R, Kachura JR, Wigg M, Cook DJ, Slutsky AS, Stewart TE (2001) Agreement between alternative classifications of acute respiratory distress syndrome. Am J Respir Crit Care Med 163:490-493
28. Villar J, Pérez-Méndez L, López J, Belda J, Blanco J, Saralegui I, SuárezSipmann F, López J, Lubillo S, Kacmarek RM, HELP Network (2007) An early PEEP/FiO2 trial identifies different degrees of lung injury in patients with acute respiratory distress syndrome. Am J Respir Crit Care Med 176:795-804

29. Klepl T, Clarkson A (2010) The world's best countries. Newsweek, 15 August 2010. http://www.newsweek.com/ 2010/08/15/interactive-infographicof-the-worlds-best-countries.html. Accessed 27 Aug 2010

30. Wunsch H, Angus DC, Harrison DA, Collange O, Fowler R, Hoste EAJ, de Keizer NF, Kersten A, Linde-Zwirble WT, Sandiumenge A, Rowan KM (2008) Variation in critical care services across North America and Western Europe. Crit Care Med 36:2787-2793

31. Strand K, Walther SM, Reinikainen M, Ala-Kokko T, Nolin T, Martner J, Mussalo P, Søreide E, Flaatten H (2010) Variations in the length of stay of intensive care unit nonsurvivors in three Scandinavian countries. Crit Care 14:R175

32. Adhikari NKJ, Fowler RA, Bhagwanjee S, Rubenfeld GD (2010) Critical care and the global burden of critical illness in adults. Lancet 375:1339-1346

33. Cavallazzi R, Marik PE, Hirani A, Pachinburavan M, Vasu TS, Leiby BE (2010) Association between time of admission to the ICU and mortality: a systematic review and metaanalysis. Chest 138:68-75

34. Laupland KB (2004) Population-based epidemiology of intensive care: critical importance of ascertainment of residency status. Crit Care 8:R431R436

35. Angus DC, Barnato AE, Linde-Zwirble WT, Weissfeld LA, Watson RS, Rickert T, Rubenfeld GD, Robert Wood Johnson Foundation ICU, End-Of-Life Peer Group (2004) Use of intensive care at the end of life in the United States: an epidemiologic study. Crit Care Med 32:638-643

36. Brower RG, Lanken PN, MacIntyre N, Matthay MA, Morris A, Ancukiewicz M, Schoenfeld D, Thompson BT, National Heart Lung AND Blood Institute ARDS Clinical Trials Network (2004) Higher versus lower positive end-expiratory pressures in patients with the acute respiratory distress syndrome. N Engl J Med 351:327-336
37. Villar J, Kacmarek RM, Pérez-Méndez L, Aguirre-Jaime A (2006) A high positive end-expiratory pressure, low tidal volume ventilatory strategy improves outcome in persistent acute respiratory distress syndrome: a randomized, controlled trial. Crit Care Med 34:1311-1318

38. Meade MO, Cook DJ, Guyatt GH, Slutsky AS, Arabi YM, Cooper DJ, Davies AR, Hand LE, Zhou Q, Thabane L, Austin P, Lapinsky S, Baxter A, Russell J, Skrobik Y, Ronco JJ, Stewart TE, Lung Open Ventilation Study Investigators (2008) Ventilation strategy using low tidal volumes, recruitment maneuvers, and high positive end-expiratory pressure for acute lung injury and acute respiratory distress syndrome: a randomized controlled trial. JAMA 299:637-645

39. Mercat A, Richard JC, Vielle B, Jaber S, Osman D, Diehl JL, Lefrant JY, Prat G, Richecoeur J, Nieszkowska A, Gervais C, Baudot J, Bouadma L, Brochard L, Expiratory Pressure (Express) Study Group (2008) Positive end-expiratory pressure setting in adults with acute lung injury and acute respiratory distress syndrome. JAMA 299:646-655

40. Cooke CR, Kahn JM, Caldwell E, Okamoto VN, Heckbert SR, Hudson LD, Rubenfeld GD (2008) Predictors of hospital mortality in a population-based cohort of patients with acute lung injury. Crit Care Med 36:1412-1420

41. Villar J, Slutsky AS (2010) Is acute respiratory distress syndrome an iatrogenic disease? Crit Care 14:120

42. Phua J, Badia JR, Adhikari NKJ, Friedrich JO, Fowler RA, Singh JM, Scales DC, Stather DR, Li A, Jones A, Gattas DJ, Hallett D, Tomlinson G, Stewart TE, Ferguson ND (2009) Has mortality from acute respiratory distress syndrome decreased over time? Am J Respir Crit Care Med 179:220-227 